\title{
KEHIDUPAN SOSIAL EKONOMI MASYARAKAT SEKUPANG YANG BERPROFESI SEBAGAI SUPIR TAXI TAHUN 2010 s/d 2016
}

\author{
Putri Eka Sari ${ }^{1}$, Arnesih $^{2}$ \\ Prodi Pendidikan Sejarah, Universitas Riau Kepulauan, Batam \\ arnesih1303@gmail.com
}

\begin{abstract}
Abstrak
Penelitian ini adalah penelitian kualitatif deskriptif dengan pendekatan ilmu sosial dan ekonomi. Metode yang digunakan ada beberapa tahap yang diantaranya (1) teknik pengumpulan data yang terdiri dari observasi, wawancara dan dokumentasi (2) analisis data yang terdiri dari reduksi data, penyajian data dan penarikan kesimpulan (3) keabsahan data dengan menggunakan teknik triangulasi data. Penelitian ini menunjukkan bahwa faktor pendorong masyarakat memilih profesi sebagai supir taxi karena dahulunya profesi ini memiliki penghasilan yang tinggi, menurut infoman, pada tahun 90-an pekerjaan yang relative mudah didapat adalah pekarjaan supir taxi, dan waktu kerjanya dalam profesi ini yang fleksibel dan tidak memiliki kontrak kerja. Supir taxi di Kecamatan Sekupang rata-rata pendidikan mereka adalah lulusan SMP sampai SMA. Agama yang dimiliki oleh supir taxi di Kecamatan Sekupang lebih dominan beragama Islam, tetapi ada juga yang beragama selain Islam. Jumlah anak yang dimiliki setiap oleh supir taxi di Kecamatan Sekupang ada yang terdiri dari dua orang hingga tiga orang anak dalam satu keluarga. Status perkawinan setiap supir taxi di Kecamatan Sekupang sudah bersatus berkeluarga. Masyarakat Tiban Lama yang berprofesi sebagai supir taxi di kecamatan sekupang belum memiliki jaminan kesehatan, hanya apabila sakit mereka hanya menggunkan uang pribadi saja. Supir taxi di Kecamatan Sekupang berasal dari bermacam-macam daerah, tetapi lebih mendominan banyak yang berasal dari daerah Sumatra Barat. Pendapatan yang dapat di peroleh sangat menurun sedikit dibandingkan pendapatan pada dahulu tahun 90-an, yang dalam sehari hanya mendapatkan Rp. 50.000 sampai Rp. 100.000.

Kata Kunci: Kehidupan Sosial Ekonomi, Supir Taxi, Kecamatan Sekupang
\end{abstract}

\section{Abstract}

This research is a descriptive qualitative research with social and economic science approach. The method used there are several stages including (1) data collection techniques consist of observation, interview and documentation (2) data analysis consisting of data reduction, data presentation and conclusion (3) data validity by using data triangulation technique. This research indicates that the factors driving people to choose the profession as a taxi driver because in the former this profession has a high income, according to the infoman in the 90's only job there is taxi driver taxi jobs, and his working time in this profession is flexible and has no contract work. Taxi drivers in Sekupang Sub-district average their education is graduated from junior high school to high school. Religion owned by taxi drivers in Sekupang Sub-district is more dominant in Islam, but it is not possible that there is no religion. The number of children owned by each taxi driver in Sekupang District consists of two people up to three children in one 
family. The marital status of each taxi driver in Sekupang Sub-district is already family. Old Tiban people who work as a taxi driver in the district sekupang not have health insurance, only if their illness only use personal money only. Taxi drivers in Sekupang Sub-district come from a variety of regions, but more dominates many who come from the West Sumatra region. Revenue that can be obtained very decreased slightly compared to income in the early 90's, which in a day only get $R p$. 50,000 to Rp. 100,000.

Keywords: Socio-Economic Life, Taxi Driver, Sekupang Sub-district

\section{PENDAHULUAN}

Kota Batam merupakan Kota yang terletak di bagian barat negara Indonesia.Batam sebuah Kota yang terletak di Provinsi Kepulauan Riau yang berbatasan langsung dengan negaranegara tetangga, yaitu Singapura, Malaysia, dan Thailand.Kota Batam dikelilingi oleh Selat Singapura dan Selat Malaka.Batam menjadi salah satu Kota terbesar di Pulau Sumatra setelah Medan, Palembang, dan Pekanbaru.

Kota Batam dikenal dengan Kota industri hal ini membuat banyak menarik perhatian masyarakat diluar Batam berdatangan yang ingin mengubah kehidupan dengan bekerja di Kota Batam, sehingga semakin lama persaingan di Kota Batam dalam mendapatkan pekerjaan sangat sulit. Masyarakat yang berdatanggan biasanya memilih berkerja sebagai karyawan perindustrianperindustrian asing, itu karena upah yang didapatkan lumayan tinggi dibandingkan dengan pekerjaan lain. Ditambah lagi setiap tahunnya upah minimum kota Batam semakin meningkat, tapi tidak semua masyarakat pendatang memilih bekerja menjadi karyawan disebuah industri, banyak juga yang memilih menjadi pedangang, bekerja di instansi pemerintahan, supir angkutan umum, dan taxi. Penduduk pendatang yang memilih menjadi profesi sebagi supir angkutan umum dan taxi dikarenakan dalam mendapatkan pekerjaan sudah semakin sulit, selain dari pada itu bekerja sebagai profesi supir taxi tidak memiliki kontrak seperti pekerjaan lainnya, jam kerja juga bebas, dan pendapatan sopir taxi pada tahun 2010 cukup besar.

Berdasarkan observasi, dapat dilihat bahwa daerah Kecamatan Sekupang menjadi salah satu daerah yang banyak di lalui kendaraan transportasi umum jasa taxi dan busway. Kendaraan umum yang sering dilalui di daerah Tiban Kecamatan Sekupang dapat dilihat beberapa yaitu jasa taxi, busway dan jasa ojek. Berbeda dengan taxi yang masih ada pengguna jasanya walaupun tidak banyak, jasa ojek sudah mulai tidak diminati lagi, sampai pada tahun 2017 mulai adanya ojek online, selain dari pada itu dikarena semakin bertambah tahun dan berkembangnya 
masyarakat sudah banyak yang memiliki kendaraaan pribadi terutama kendaraan roda dua. Untuk jasa transportasi carry seperti yang digunakan masyarakat daerah Batu Aji tidak ada rute yang melintasi di di wilayah kecamatan Sekupang dan wilayah Tiban, hal itu dikarenakan dari Pemerintah Kota tidak adanya trayek atau rute (jalan yang dilalui) di wilayah kecamatan Sekupang, dan juga masyarakat Tiban Kecamatan Sekupang sudah terbiasa yang menggunakan jasa taxi dan busway dibandingkan menggunakan jasa angkutan umum carry seperti di Batu Aji. Kecamatan Sekupang yang berprofesi sebagai supir taxi mengalami persaingan dengan angkutan umum busway, taxi online, dan sesama taxi konvensional, karena sama-sama mencari pendapatan di jalanan. Keberadaan busway yang mulai beroperasi di Kota Batam sejak tahun 2005, awalnya jam operasional busway yang hanya dari pukul 7 pagi hingga pukul 6 sore dengan hanya memiliki 2 koridor yaitu koridor Sekupang hingga Batam Center, Batam Center hingga Sekupang dan koridor Batu Aji hingga Batam Center, Batam Center hingga Batu Aji. Tidak hanya itu dengan sesama pengendara jasa taxi pasti mengalami persainggan dalam mencari penumpang di jalan raya apa lagi dengan jasa transportasi umum lainya.

Berdasarkan observasi, dapat dilihat bahwa daerah Kecamatan Sekupang menjadi salah satu daerah yang banyak di lalui kendaraan transportasi umum jasa taxidanbusway.Kendaraan umum yang sering di daerah Tiban Kecamatan Sekupang dapat dilihat beberapa yaitu jasa taxi, busway dan jasa ojek. Berbeda dengan taxi yang masih ada pengguna jasanya walaupun tidak banyak, jasa ojek sudah mulai tidak diminati lagi, sampai pada tahun 2017 mulai adanya ojek online, selain dari pada itu dikarena semakin bertambah tahun dan berkembangnya teknologi masyarakat sudah banyak yang memiliki kendaraaan pribadi terutama roda dua. Untuk jasa transportasi carry seperti carry yang digunakan masyarakat daerah Batu Aji tidak terdapat di daerah kecamatan Sekupang Tiban. Hal itu dikarenakan dari Pemerintah Kota tidak adanya trayek (jalan yang dilalui) di wilayah kecamatan Sekupang, dan juga masyarakat Tiban Kecamatan Sekupang sudah terbiasa yang menggunakan jasa taxi dan busway dibandingkan menggunakan jasa angkutan umum carry seperti di Batu Aji. Kecamatan Sekupang yang berprofesi sebagai supir taxi mengalami persaingan dengan angkutan umum busway, taxionline, dan sesama taxi konvensional, karena sama-sama mencari pendapatan di jalanan. Keberadaan busway yang mulai beroperasi di Kota Batam sejak tahun 2005, awalnya jam operasional busway yang hanya dari pukul 7 pagi hingga pukul 6 sore dengan hanya memiliki 2 koridor yaitu koridor Sekupang 
hingga Batam Center, Batam Center hingga Sekupang dan koridor Batu Aji hingga Batam Center, Batam Center hingga Batu Aji. Tidak hanya itu dengan sesama penggendara jasa taxi pasti mengalami persainggan dalam mencari penumpang di jalan apa lagi dengan jasa transportasi umum lainya.

Berkenaan dengan meningkatnya jumlah transportasi umum terutama jasa angkutan umum yang berbasis online, mengakibatkan jumlah pendapatan supir taxi menurun drastis. tidak bisa dipungkiri keberadaan teknologi canggih yang membuat dan memberikan banyak manfaat kemudahan dalam menjalankan aktivitas tranfortasi hingga masyarakat yang berada diwilayah sekupang pun lebih tertarik menggunakan jasa transportasi berbasis online.

Penelitian ini bertujuan untuk mengetahui kehidupan sosial-ekonomi supir taxi di kecamatan Sekupang, dan faktor yang menyebabkan para supir taxi memilih profesi ini. Adapun dari penelitian ini diharapkan dapat menjadi masukan khususnya bagi pemerintah Kota Batam dalam masalah ketenagakerjaan dan permasalahan pendidikan. Penelitian ini juga dapat digunakan sebagai rujukan dan komparasi bagi peneliti lain dalam kajian yang berkaitan.

\section{METODE PENELITIAN}

Penelitian ini merupakan penelitian kualitatif. Penelitian kualitatif merupakan penelitian yang memanfaatkan wawancara terbuka untuk menelaah dan memahami sikap, pandangan, perasaan, dan perilaku individu atau kelompok orang (Moleong, 2013:5).

Metode penelitian ini menggunakan metode kualitatif deskriptif dengan dengan pendekatan ilmu sosial ekonomi. Adapun metode yang digunakan ada beberapa tahap (1) Teknik pengumpulan data (2) analisis data yang yang terdiri dari reduksi data, penyajian data dan penarikan kesimpulan (Sugiyono, 2014: 25).

\section{HASIL PENELITIAN DAN PEMBAHASAN}

\section{Gambaran Umum Lokasi Penelitian}

\section{a. Kota Batam}

Kota Batam merupakan salah satu wilayah yang terletak di Kepulauan Riau. Kota Batam lebih dikenal sebagai kota industri karena banyaknya perindustrian yang berdiri di kota Batam sendiri. 
Secara geografis kota Batam terletak berada di jalur pelayaran dunia

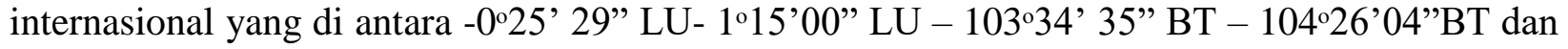
berbatasan langsung dengan Singapura dan Malaysia. Batam memiliki luas wilayah $3.829,93 \mathrm{Km}^{2}$, yang terdiri dari luas wilayah darat $1.038, \mathrm{Km}^{2}$ dan luas wilayah laut $2.791 \mathrm{Km}^{2}$ (http://batam.go.id/profil-geografis.html).

\section{b. Kecamatan Sekupang}

Berdasarkan data kecamatan Sekupang yang dikutip oleh Badan Pusat Statistik Kota Batam 2015 Kecamatan Sekupang memiliki luas 106,78 $\mathrm{km}^{2}$ dengan jumlah penduduk pada tahun 2014 mencapai 123.972 jiwa dan kepadatan 868 jiwa $/ \mathrm{km}^{2}$ jumlah penduduk ini semakin meningkat setiap tahunnya. Kecamatan Sekupang memiliki delapan kelurahan yang terdiri dari kelurahan Tiban Asri, Kelurahan Tanjung Riau, Kelurahan Tiban Lama, Kelurahan Tiban Baru, Kelurahan Tiban Indah, Kelurahan Patam Lestari, Kelurahan Sungai Harapan, dan Kelurahan Tanjung Pinggir. Wilayah Kecamatan Sekupang terdiri dari pulau besar dan kecil dengan penyebaran penduduk yang tidak merata (Badan Pusat Statistik Kecamatan Sekupang, 2015).

\section{c. Tiban Lama}

Tiban Lama merupakan salah satu daerah yang berada di kelurahan Tiban Lama yang masih dalam satu kawasan di kecamatan Sekupang. Tiban Lama memiliki luas wilayah $14.094 \mathrm{~km}^{2}$, dengan jumlah penduduk awal 7.148 kepala keluarga dan 19.534 anggota keluarga, hingga tahun 2017 jumlah penduduk Tiban Lama yang telah di data berjumlah 7.118 kepala keluarga dan 19.504 anggota keluarga. Jumlah penduduk dari tahun ke tahun mengalami peningkatan. Hal ini disebabkan karena adanya angka kelahiran dan adanya penduduk pendatang yang datang ke daerah ini.

\section{Gambaran Khusus Lokasi Penelitian}

\section{a. Jumlah Supir Taxi di Kecamatan Sekupang}

Kecamatan Sekupang memiliki dua pangkalan resmi taxi yang pertama itu pangkalan taxi di pelabuhan Ferry Internasional Sekupang dengan organisasi PEPTIS yang memiliki anggota sebanyak 83 orang yang memang terdiri dari beberapa koperasi yang bergabung dalam satu organisasi dan yang kedua pelabuhan Ferry Domestik Sekupang dengan organisasi merah putih yang memiliki anggota sebanyak 200 orang yang bergabung dalam satu organisasi. 


\section{b. Organisasi PEPTIS}

PEPTIS singkatan dari Persatuan Pengemudi Taxi Internasional Sekupang yang merupakan organisasi resmi taxi yang berada di pelabuhan internasional Sekupang.Organisasi PEPTIS berdiri dari tahun 2007 yang di ketuai oleh Bapak Afdial yang berprofesi sebagai supir taxi dengan jumlah anggota 83 supir taxi.

\section{Faktor Penyebab Memilih Profesi sebagai Supir Taxi}

Berdasarkan hasil pengumpulan data, terdapat beberapa faktor yang menyebabkan banyaknya masyarakat beralih profesi sebagai supir taxi. Yang pertama adalah karena pada saat itu pendapatan yang diperoleh supir taxi dalam sehari dapat mencapai Rp. 700.000 s/d Rp. 800.000. Selanjutnya, pada saat itu jenis pekerjaan belum sebanyak pada saat sekarang ini. Profesi supir taxi pada tahun 2010 menjadi salah satu alternatif dari berbagai profesi yang ada. Selain pendapatan yang diperoleh tinggi, jam kerja pada profesi ini sangat fleksibel, dan tidak memiliki kontrak. Hal inilah yang mendorong masyarakat yang sudah bekerja beralih profesi sebagai supir taxi.

\section{Kehidupan Sosial Ekonomi}

\section{a. Pendidikan}

Pendidikan merupakan sesuatu yang sangat penting untuk menunjang kehidupan seseorang kedepannya, agar perekonomian keluarga mereka lebih baik lagi, dan lebih banyak pengetahuan di bidang masing-masing terutama masyarakat yang berprofesi sebagai supir taxi. Berdasarkan hasil wawancara dengan beberapa orang supir taxi, pendidikan terakhir yang ditempuh oleh masyarakat yang berprofesi sebagai supir taxi di kecamatan Sekupang terdiri adalah sekolah menengah pertama (SMP) dan sekolah menengah atas (SMA).

\section{b. Jumlah Anak}

Masyarakat Sekupang yang berprofesi sebagai supir taxi memiliki beberapa anak dalam keluarganya. Berdasarkan data pribadi yang didapatkan dari informan, mereka yang berprofesi sebagai supir taxi di Kecamatan Sekupang memiliki 2 sampai 3 orang anak dalam satu keluarga. 


\section{c. Satus Perkawinan}

Berdasarkan dari data pribadi yang didapatkan dari informan, Satus perkawinan setiap masyarakat Sekupang yang berprofesi sebagai supir taxi di Kecamatan Sekupang memiliki status sudah berkeluarga atau menikah.

\section{d. Kesehatan}

Supir taxi di daerah kecamatan Sekupang tidak memiliki jaminan kesehatan dari pemerintah seperti BPJS dan lain-lainya. Hanya saja apabila saat salah satu rekan sesama profesi sakit dan terkena musibah, kebiasaan yang dilakukan oleh supir taxi di kecamatan Sekupang memberi sumbangan sukarela dari pribadi masing-masing untuk meringankan beban dari rekan satu profesi.

\section{e. Pendapatan}

Profesi supir taxi di Kota Batam sudah beroperasi sebelum tahun 1990-an. Pada saat itu banyak masyarakat pendatang memilih dan beralih profesi menjadi supir taxi dikarenakan pendapatan yang dihasilkan dari profesi ini dapat memenuhi kebutuhan rumah tangga bahkan sampai dapat menyekolahkan anaknya ke perguruan tinggi.

\section{KESIMPULAN DAN SARAN}

Supir taxi yang ada di Kecamatan Sekupang banyak berasal dari luar Kota Batam, dengan mayoritas dari suku Minang. Tingkat pendidikan mereka pada umumnya adalah SMP dan SMA. Profesi ini tidak memiliki banyak persyaratan, asalkan memiliki skil dalam mengemudi mobil maka dapat melakukan profesi ini. Pendapatan yang diperoleh sebagai supir taxi dapat memenuhi kebutuhan rumah tangga. Terdapat dua pangkalan taxi yang ada di kecamatan Sekupang, yaitu yang terletak di Pelabuhan Domestik Sekupang dan Pelabuhan Internasional Sekupang. Setiap pangkalan memiliki organisasi masing-masing yang terdiri dari beberapa koperasi khususnya di pangkalan internasional. Supir taxi di kecamatan Sekupang rata rata tidak memiliki jaminan kesehatan dari manapun. Hal yang dilakukan oleh para supir taxi apabila ada rekan seprofesi mengalami musibah adalah memberi sumbangan seikhlasnya.

Berdasarkan temuan di lapangan, penulis menyarankan kepada pemerintah Kota Batam agar dapat memperhatikan kesejahteraan supir taxi dan memperkenalkan lagi supir taxi yang ada 
di Kota Batam kepada pendatang atau turis yang berdatangan ke kota Batam. Dengan demikian, permasalahan dalam pendapatan yang diperoleh supir taxi dapat menjadi lebih baik lagi. Selanjutnya, Pemerintahan Kota Batam diharapkan tidak menambah lagi organisasi yang sejenis yang berhubungan dengan transportasi darat untuk kedepannya. Peneliti selanjutnya agar dapat menyempurnakan lagi penelitian ini dengan menambahkan hal-hal yang berkembang di dalam ruang lingkup profesi supir taxi kedepannya.

\section{DAFTAR PUSTAKA}

Badan Pusat Statistik Kota Batam. 2015. Kecamatan Sekupang Dalam Angka (No. Publikasi 2171.15.15 Katalog BPS 1102001.2171.060). Batam: Badan Pusat Statistik Kota Batam. diambil pada tanggal 3 Agustus 2017, dari https://batamkota.bps.go.id/website/pdf_publikasi/Kecamatan-Sekupang-

Dalam-Angka-2015.pdf. pada pukul 11:03

Kantor Kelurahan Tiban Lama. Laporan Kependudukan.

Moleong, J.L. 2012. Metodologi Penelitian Kualitatif. Bandung: PT Remaja Rosdakarya

Pemerintahan Kota Batam. Profil Geografis Kota Batam diambil pada tanggal 30 juli 2017, dari (http://batam.go.id/profil-kependudukan.html/) pada pukul $22: 30$

Sugiyono. 2014. Metode Penelitian Kuantitatif Kualitatif Dan $R \& D$. Bandung: Alfabeta.

Damsar.2009 Pengantar sosiologi ekonomi, Jakarta: kencana pranata Media group Paisal, Sanapiah, 2007, Format penulisan penelitian sosial, Jakarta: PT raja grafindo 